\title{
Meteorological table, for June 1807
}

\section{Mr. Carey}

To cite this article: Mr. Carey (1807) Meteorological table, for June 1807, Philosophical Magazine Series 1, 28:109, 96-96, DOI: 10.1080/14786440708563487

To link to this article: http://dx.doi.org/10.1080/14786440708563487

$$
\text { 册 Published online: } 18 \text { May } 2009 .
$$

Submit your article to this journal 준

LII Article views: 3

Q View related articles $\asymp$ 
METEOROLUGICAL TABLE, By Mr. Carey, of the Strand,

For June 1807.

\begin{tabular}{|c|c|c|c|c|c|c|}
\hline \multirow[b]{2}{*}{$\begin{array}{l}\text { Days of the } \\
\text { Month. }\end{array}$} & \multicolumn{3}{|c|}{ Thermometer. } & \multirow[b]{2}{*}{$\begin{array}{c}\text { Height of } \\
\text { the B̃arom. } \\
\text { Inches. }\end{array}$} & \multirow{2}{*}{ 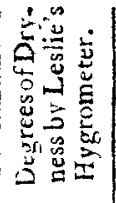 } & \multirow[b]{2}{*}{ Weather. } \\
\hline & 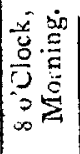 & $\begin{array}{l}\dot{\Xi} \\
\text { ż }\end{array}$ & 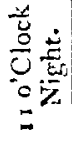 & & & \\
\hline May 27 & $51^{\circ}$ & $64^{\circ}$ & $52^{\circ}$ & $29 \cdot 9.5$ & 41 & Fair \\
\hline 28 & 52 & 66 & 47 & .84 & 52 & Fair \\
\hline 29 & 48 & 57 & 43 & $\cdot 68$ & 30 & Cloudy \\
\hline 30 & 43 & 45 & 46 & $\cdot 61$ & 0 & $\begin{array}{l}\text { Rain, and re- } \\
\text { markable bigh } \\
\text { wind. }\end{array}$ \\
\hline 31 & 49 & 56 & 44 & $\cdot 82$ & 15 & Showery \\
\hline June 1 & 47 & 58 & 49 & .80 & 17 & Showery \\
\hline 2 & 49 & 57 & 51 & $\cdot 92$ & 20 & Showery \\
\hline 3 & 46 & 57 & 46 & $30 \cdot 00$ & 21 & Fair \\
\hline 4 & 54 & 60 & 53 & $\cdot 11$ & 37 & Fair \\
\hline 5 & 55 & 57 & 52 & $\cdot 07$ & 30 & Cloudy \\
\hline 6 & 54 & 56 & 50 & $29 \cdot 90$ & 0 & Rain \\
\hline 7 & 47 . & 48 & 46 & $\cdot 62$ & 0 & Rain \\
\hline 8 & 47 & 63 & 55 & $\cdot 63$ & 42 & Fair \\
\hline 9 & 56 & 65. & 56 & .78 & 52 & Fair \\
\hline 10 & 57 & 65 & 54 & $30 \cdot 02$ & 28 & Cloudy \\
\hline 11 & 55 & 67 & 56 & .02 & 21 & Cloudy \\
\hline 12 & 57 & 68 & 52 & $\cdot 14$ & 35 & Fair \\
\hline 13 & 58 & 69 & 51 & $\cdot 20$ & 51 & Fair \\
\hline 14 & 55 & 67 & 55 & .11 & 30 & Cloudy \\
\hline 15 & 56 & 76 & 64 & $29 \cdot 92$ & 56 & Fair \\
\hline 16 & 58 & 71 & 60 & .72 & 61 & Fair \\
\hline 17 & 56 & 67 & 56 & $\cdot 98$ & 58 & Fair \\
\hline 18 & 55 & 64 & 54 & 30.07 & 61 & Fair \\
\hline 19 & 55 & 65 & 55 & .21 & 62 & Fair \\
\hline 20 & 57 & 67 & 54 & $\cdot 22$ & 63 & Fair \\
\hline 21 & 58 & 73 & 62 & -36 & 64 & Fair \\
\hline 22 & 59 & 71 & 61 & $\cdot 15$ & 55 & Fair \\
\hline 23 & 60 & 68 & 55 & $\cdot 13$ & 54 & Fair \\
\hline 24 & 57 & 74 & 60 & .01 & 46 & Fair \\
\hline 25 & 60 & 75 & 55 & $29 \cdot 88$ & 59 & Fair \\
\hline 26 & 56 & 69 & 64 & .96 & 41 & Fair \\
\hline
\end{tabular}

N. B. The Barometer's height is taken as one o'cleck. 